\title{
Divided Flow, Low-Temperature Humidity Test Apparatus
}

\author{
By Arnold Wexler
}

\begin{abstract}
An apparatus is described, based on the principle of divided flow, for producing air of known relative humidity at temperatures below $0^{\circ} \mathrm{C}$ with an average error of 3 percent. It was designed primarily for testing and calibrating at low temperature the electric-hygrometer elements used in radiosondes, although any device with a diameter less than $1 \frac{1}{8}$ in. may be inserted into the test chamber of the apparatus. It is capable of producing rapid and discrete changes in relative humidity at constant temperature, a desirable feature for studying lag characteristics. It is provided with a control for obtaining any air velocity up to $1,500 \mathrm{ft} / \mathrm{min}$.
\end{abstract}

\section{Introduction}

An apparatus has been developed for producing air of known relative humidity at temperatures from $0^{\circ}$ to $-40^{\circ} \mathrm{C}$. The primary purpose for building this apparatus was to provide a means for investigating the behavior of radiosonde hygrometers at low temperatures, especially electrichygrometer elements of the Dunmore type. In their use, on radiosondes, the elements are subjected to rapidly changing humidity conditions and to air velocities of about $700 \mathrm{ft} / \mathrm{min}$. It was felt desirable in studying and calibrating these elements to be able to do so under simulated conditions of use. Therefore, in the design of the apparatus, provision was made to permit rapid change from one discrete value of relative humidity to another, and a device was incorporated for controlling the velocity of the air.

\section{Theory}

The method utilized for producing an atmosphere of known relative humidity was to divide accurately a current of dry air into two streams, one of which was maintained dry and the other saturated with respect to ice, and then to recombine the two. It was employed by Gluckauf ${ }^{2}$ in

\footnotetext{
1 This development was financially supported by the Bureau of Ships, Department of the Navy.

2 E. Gluckauf, Proc. Phys. Soc. 59, 344 (1947).
}

an investigation on absorption hygrometers and by Walker and Ernst, $\mathrm{Jr}^{3}$ in a laboratory setup for preparing constant mixtures of air and water vapor. Figure 1 is a simplified schematic diagram of the basic components of the apparatus illustrating the principle of operation. By means of the proportioning valve, $V$, a flow of moisture-free air is divided into two parts in a known ratio. One part is passed through the saturator, $S$, over a series of trays containing ice until it is completely saturated. It is then mixed in the mixing chamber, $C_{M}$, with the other part that has been maintained dry, and allowed to exhaust through the

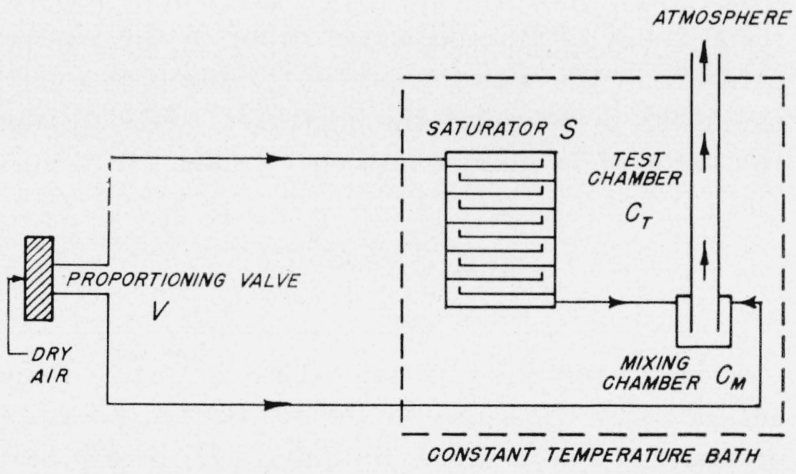

Figure 1. Simplified schematic diagram illustrating the principle of operation of the humidity apparatus.

${ }^{3}$ A. C. Walker and E. J. Ernst, Jr., Ind. \& Eng. Chem. Anal. Ed. 2, 134 (1930). 
test chamber, $C_{T}$, into the atmosphere. The saturator, mixing chamber, and test chamber are kept immersed in a constant temperature bath. In order to subject a hygrometer or other device to air of known and constant relative humidity, it is inserted into the test chamber, $C_{T}$.

The relative humidity in the test chamber is a function of (a) the fraction of air that passes through the saturator, (b) the total pressure in the saturator, (c) the total pressure in the test chamber, (d) the saturation pressure, and (e) the partial pressure of the water vapor in the test chamber. Under ideal conditions, which the apparatus approaches with sufficient closeness, all variables except one drop out, and the relative humidity becomes equal to the fraction of air that passes through the saturator. If $X$ is the fraction of air that passes through the saturator, $W_{S}$ is the ratio by weight of the water vapor to the dry air of the mixture leaving the saturator, and $W_{C}$ is the ratio by weight of the water vapor to the dry air of the mixture passing through the test chamber, then

$$
W_{C}=X W_{S} .
$$

From Dalton's law of partial pressures, and assuming the perfect gas laws apply, it follows that for an air-water vapor mixture the ratio by weight $W$ of the water vapor to the weight of dry air is

$$
W=\frac{M_{w}}{M_{a}} \frac{p}{P-p},
$$

where $M_{a}$ and $M_{w}$ are the molecular weights respectively of air and water vapor, $p$ the partial pressure of the water vapor in the mixture and $P$ the total pressure of the mixture. Substituting the value of $W$ in eq 2 into eq 1 yields

$$
X=\frac{\left(P_{S}-p_{S}\right) p_{C}}{\left(P_{C}-p_{C}\right) p_{S}}
$$

Relative humidity is defined as the ratio of the actual vapor pressure to the saturation pressure of water. The relative humidity, $H$, in the test chamber, $C_{T}$, is therefore

$$
H=\frac{p_{C}}{p_{S}} .
$$

Combining eq 3 and 4 leads to

$$
H=\frac{X}{\left(\frac{P_{S}}{P_{C}}-\frac{p_{S}}{P_{C}}\right) \frac{P_{C}}{P_{C}-p_{C}}} .
$$

If the pressure drops from the saturator to the test chamber and from there to the atmosphere are made small, then $P_{S}=P_{C}=P_{A}$, the atmospheric pressure. At $0^{\circ} \mathrm{C}, p_{S} / P_{C}=p_{S} / P_{A}=0.006$, at $-10^{\circ} \mathrm{C}$ it equals 0.0025 , and at $-20^{\circ} \mathrm{C}$ it equals 0.001 . Also $P_{C} / P_{C}-p_{C}=P_{A} / P_{A}-p_{C}$, where $p_{C}$ equals or is less than $p_{S}$. Therefore, for the applicable conditions eq 5 reduces without significant error to

$$
H=X \text {. }
$$

\section{Description of Apparatus}

The essential functional units of the apparatus are (a) the drying system, (b) the proportioning system, (c) the humidifying system, (d) the mixing chamber, (e) the test chamber, (f) the cooling system, and $(\mathrm{g})$ the thermo-regulating system for temperature control. Figure 2 schematically shows these functional units and their component parts.

Air is supplied to the drying system at pressures from 70 to 90 psi. Water from the air at the supply pressure is removed by freezing in the dry ice-varsol bath, $C 1$, in which the temperature is well below $-70^{\circ} \mathrm{C}$. The vapor pressure of the water in the air emerging from the drying system, upon expansion to 1 atmosphere, is probably less than $0.0003 \mathrm{~mm} \mathrm{Hg}$. Particles of dirt, ice, or oil are caught by the filter, $A 8$.

The dry air is brought to room temperature by means of the electric heater, $A 10$, is reduced and controlled in pressure by regulator, $A 12$, and then passes through the proportioning system. The pressure regulator also serves to control the speed of air in the test chamber, A25, permitting adjustments up to $1,500 \mathrm{ft} / \mathrm{min}$.

The proportioning valve, $A 15$, figure 2 , which divides the air in a definite ratio consists of six orifices of equal cross-sectional area so arranged that by a turn of the knob of the valve, the incoming air can be divided to produce any of seven ratios, $0,1 / 6,1 / 3,1 / 2,2 / 3,5 / 6$, and 1 . These ratios are the fractions of air entering the valve that emerge through one of the exit channels of 


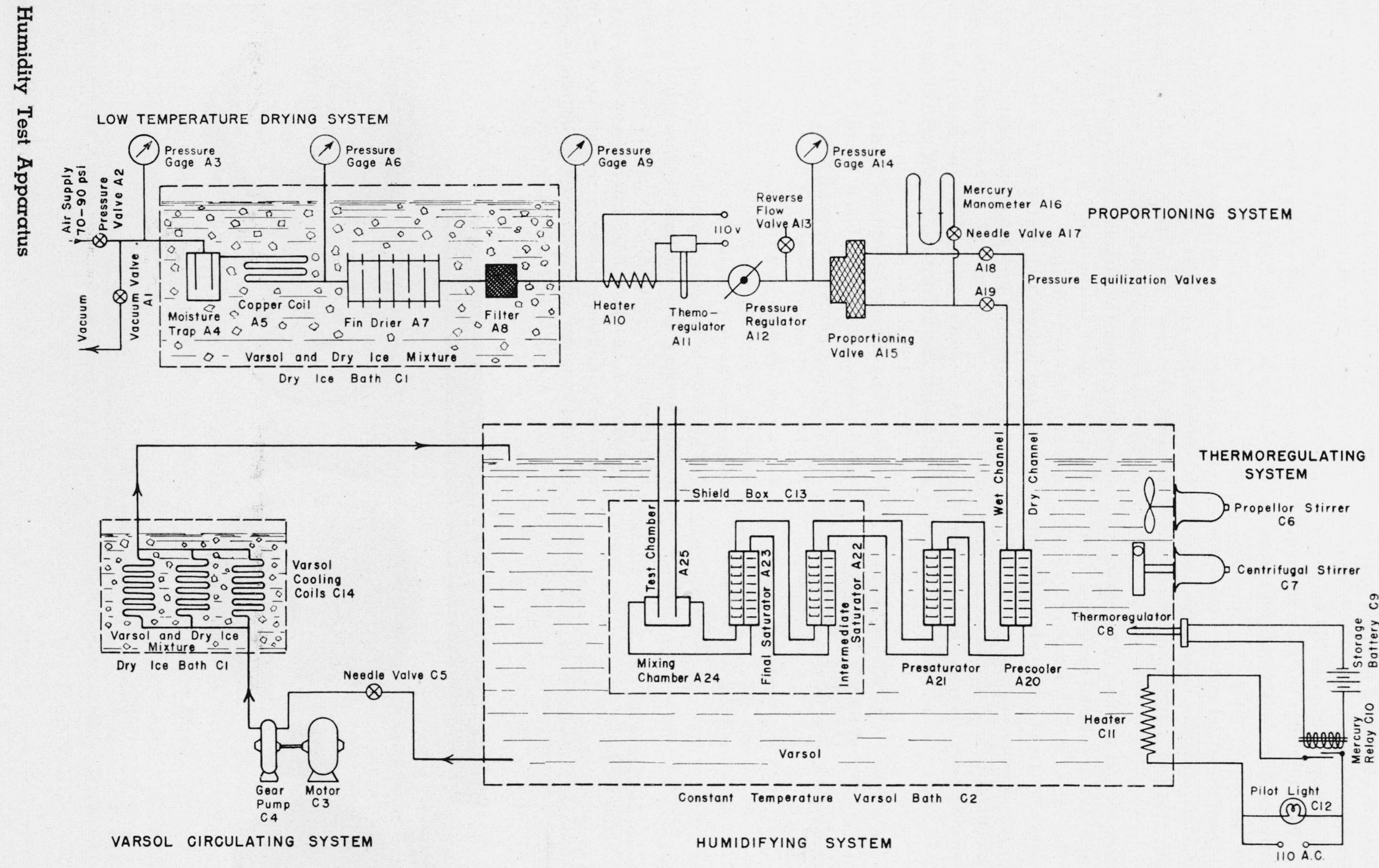

FIGURE 2. Schematic drawing of the functional units and component parts of the humidity apparatus. 
the valve. If they are considered to apply only to that part of the air that subsequently becomes saturated, then they may be used as the values of $X$ in eq 5 and 6 . To assure that the air will divide in accordance with one of these given fixed ratios, the downstream pressures must be equalized. To achieve this, the differential mercury manometer, $A 16$, and the two variable resistances (pressure equalization valves), $A 18$ and $A 19$, are installed.

The construction of, and the flow of air through, the proportioning valve are shown in figures 3 and 4. Essentially the valve, A15, consists of a brass base, $B$, a brass top, $T$, i steel orifice plate, $P$, and a Bakelite knob, $K$. The incoming air enters the valve through a central hole in the base, $B$, continues through two $3 / 16$-in. diameter holes in the

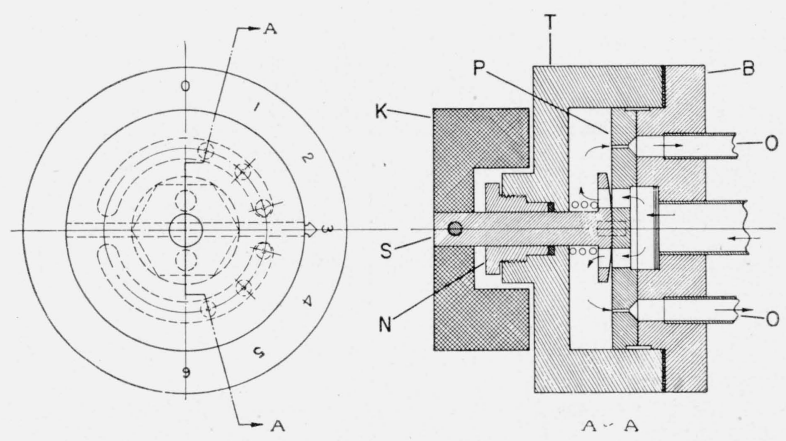

Figure 3. Cross-sectional view of the proportioning valve showing the flow of air.

$R$, Brass base; $T$, brass top; $P$, steel orifice plate; $K$, Bakelite knob; $O$, air outlet; $S$, steel shaft; $N$, steel packing nut. midsection of the orifice plate, $P$, strikes the top, $T$, reverses its flow and again passes through the steel orifice plate, $P$, this time through six 1-mm diameter orifices, and exits in two streams from the base, $B$. The base, $B$, has two circular grooves on a $1 \frac{1 / 2}{2}$ in. diameter, $3 / 16$-in. wide, $1 / 4$ in. deep and separated $1 / 4$ in. at the ends. Each groove is connected to an outlet, $O$. The orifice plate, $P$, rests on the base, $B$, in such a fashion that the orifices communicate with either or both grooves, depending upon the angular position of the plate, $P$, with respect to the base, $B$. The surfaces of contact between the plate, $P$, and base, $B$, are ground and lapped and coated with a thin film of stopcock grease to provide a leaktight but rotatable joint. By means of a steel shaft, $S$, that connects the orifice plate, $P$, to the Bakelite knob, $K$, through the valve top, $T$, and a steel packing nut, $N$, that seals the shaft, $S$, in the top, $T$, the orifice plate, $P$, can be rotated to any one of the seven possible settings. Upon turning the knob, $K$, two spring actuated snap pins, $Q$, in the knob, $K$, click and seat in a series of holes on the outer surface of the valve top, $T$, corresponding to the seven desired positions of the orifice plate, $P$, with respect to the valve base, $B$.

The two air streams, upon leaving the proportioning system, flow through the humidifying system in parallel channels, thermally in contact with one another to allow heat interchange and temperature equilibrium between the two streams to be achieved and maintained. Saturation is ac-

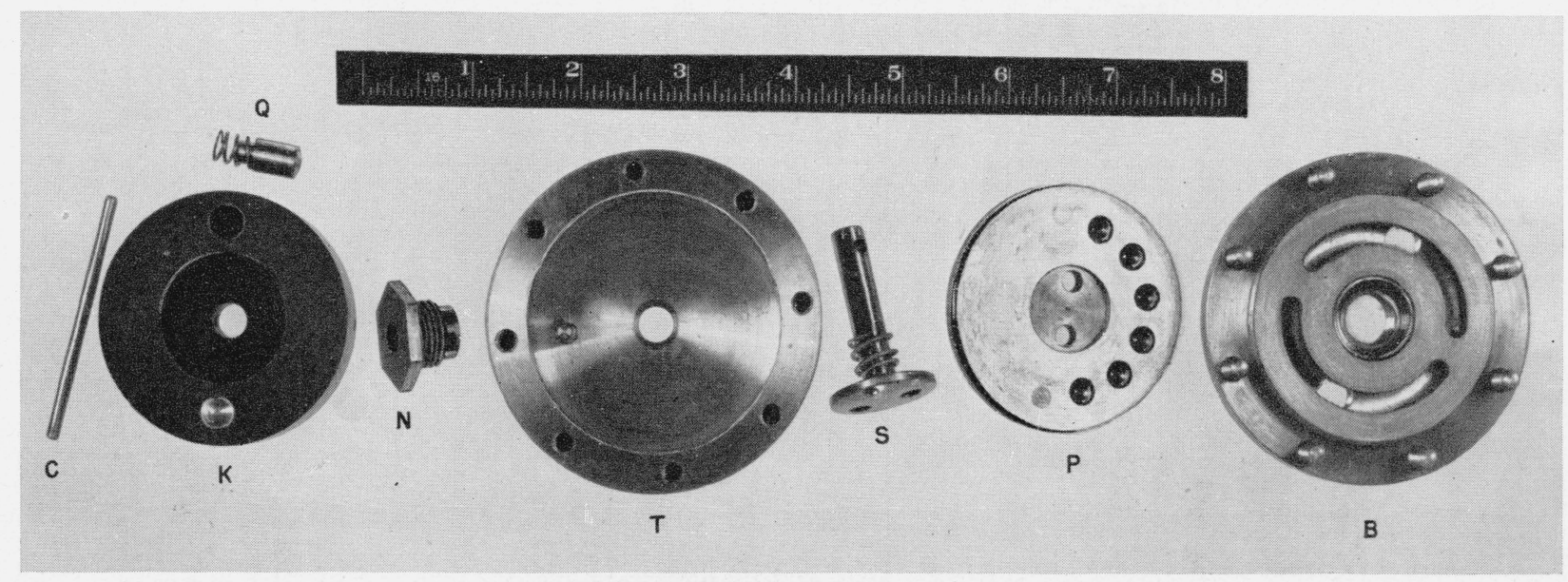

Figure 4. Essential parts of the proportioning valve.

$B$, Brass base; $P$, steel orifice plate; $S$, steel shaft; $T$, brass top; $N$, steel packing nut; $K$, Bakelite knob; Q, spring-actuated snap pin; $C$, steel pin for fastening $K$ to $S$. 
complished in four stages. The air to be humidified is first brought to ambient temperature in a precooler, A20, figure 2. It then passes through three saturators, A21, A22, and A23. The precooler, A20, consists of staggered shelves, one series for each of the two currents of air. Each series is pneumatically isolated from, but in thermal contact with, the other. The saturators are similarly built, except that trays replace one series of shelves. The trays can be filled with water and the water frozen. Thus, in the saturator, in one channel air passes over trays of ice and in the parallel adjoining channel, air passes over shelves. From the final saturator, A23, the saturated air and the dry air are centrifugally mixed in the mixing chamber, A24, and discharged into the atmosphere through the test chamber, A25.

The humidifying system, the mixing chamber, A24, and the test chamber, A25, are immersed in a varsol bath, $C 2$, whose temperature is closely regulated. This is done by circulating the varsol of the bath through cooling coils, C14, immersed in dry ice. The bimetal thermoregulator, $\mathrm{C} 8$, through the relay, $C 10$, controls the heater, $C 11$, to keep the bath termperature at any desired value. The bath, C2, is actively agitated. As an aid in averaging and stabilizing the variations of the bath temperature, the intermediate and final saturators, A22 and A23, the mixing chamber, A2.4, and the test chamber, A25, are encased in the copper shield box, $C 13$, to provide a unit of high heat content that assumes the mean tempera ture of the bath. The shield box, C13, keeps varsol away from direct contact with the enclosed components.

The thermoregulating system is capable of controlling the temperature of the humidifying system to $\pm 0.05^{\circ}$ down to $-15^{\circ} \mathrm{C}$, to $\pm 0.1^{\circ}$ down to $-30^{\circ} \mathrm{C}$ and to $\pm 0.2^{\circ}$ down to $-40^{\circ} \mathrm{C}$ for runs up to $10-\mathrm{hr}$ duration. For short periods of time of $1 / 2$ to $1 \mathrm{hr}$, the temperature can be maintained to $\pm 0.02^{\circ}$ C. Calibrated copperconstantan thermocouples and a precision potentiometer are used for measuring the temperature in the apparatus with an accuracy of $\pm 0.02^{\circ} \mathrm{C}$.

Measurements of the temperatures at the inlets and outlets in the final saturator, A23, under various conditions, indicate that at the inlets the two air streams are on the average within $0.07^{\circ} \mathrm{C}$ of one another, and at the outlets they are on the average within $0.02^{\circ} \mathrm{C}$ of one another. In the humidifying side of the final saturator, A23, the inlet and exit temperatures are on the average within $0.03^{\circ} \mathrm{C}$ of each other. The temperature in the test chamber is on the average $0.08^{\circ} \mathrm{C}$ warmer than the air emerging from the final saturator, A23.

Since no further saturation can occur subsequent to the exit of the air from the final saturator, A23, the pressure at the exit may therefore be considered as the $P_{S}$ of eq 5. The difference between $P_{S}$ and atmospheric pressure, $P_{A}$, for various test chamber air velocities, is shown in the curve of figure 5. At an air velocity

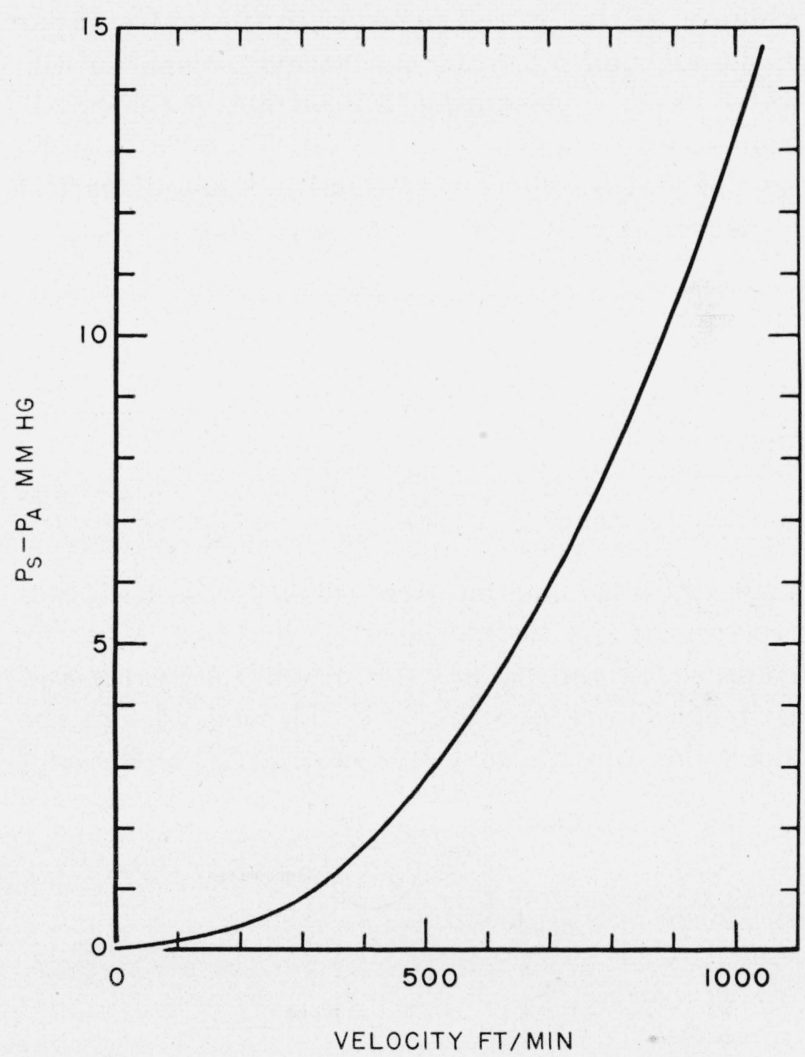

Figure 5. Difference in pressure between the exit of the final saturator, $P_{s}$, and atmospheric pressure, $P_{A}$, for various test chamber air velocities.

of $525 \mathrm{ft} / \mathrm{min}$, the assumption that $P_{S}=P_{A}$ introduces an error in $H$ of 0.4 percent, at 850 $\mathrm{ft} / \mathrm{min}$, the error is 1.2 percent, and at $1,140 \mathrm{ft} / \mathrm{min}$, the error becomes 2.5 percent. If eq 5 instead of eq 6 is used for calculating the relative humidity produced by the apparatus, these errors are avoided. 


\section{Calibration}

\section{Theory}

In order to check the over-all performance of the apparatus, a series of tests was made to compare the actual humidity it produces with the humidity given by eq 6 . The gravimetric method of moisture determination was selected as the means for measuring the water vapor content of the air in the test chamber under operating conditions. "By definition, the relative humidity in the test chamber is

$$
H=\frac{p_{w}}{p_{s w}},
$$

where $p_{v}$ is the partial pressure of the water vapor in the air, and $p_{s w}$ is the saturation pressure of the water vapor. Assuming that air and water vapor from room temperature to $-60^{\circ} \mathrm{C}$ and at a pressure of 1 atmosphere obey Dalton's law of partial pressures and the perfect gas law, then

$$
\begin{gathered}
p_{a}+p_{w}=P_{C}, \\
p_{w} V=\frac{m_{w}}{M_{w}} R T_{C},
\end{gathered}
$$

and

$$
p_{a} V=\frac{m_{a}}{M_{a}} R T_{C}
$$

where $p_{a}$ is the partial pressure and $P_{C}$ is the total pressure of the air in the test chamber, $V$ is the volume, $m_{w}$ and $m_{a}$ are the weights of water and air respectively in volume $V, M_{w}$ and $M_{a}$ are the molecular weights of water and air, $R$ is the uni- versal gas constant, and $T_{C}$ is the absolute temperature in the test chamber.

Since the air in the air-water-vapor mixture from the test-chamber exhausts with negligible pressure drop into the atmosphere, then $P_{C}=P_{A}$, where $P_{A}$ is atmospheric pressure. Dividing eq 9 by eq 10 and substituting into eq 8 yields

$$
p_{w}=\frac{P_{A}}{1+\frac{m_{a} M_{w}}{m_{w} M_{a}}} .
$$

If, from a sample of air taken from the test chamber, the weight of water vapor and air be determined and the pressure measured, the partial pressure of the water vapor could easily be calcu lated using eq 11, and the relative humidity would follow from eq 7 . Figure 6 is a schematic diagram of the setup used for obtaining $m_{a}, m_{w}$, and $P_{A}$. A glass probe was inserted into the test. chamber and a sample of air withdrawn. The water vapor was removed from the sample by passing it through an absorption tube containing phosphorous pentoxide and accurately weighed. The volume, pressure, and temperature of the same sample of air were measured, and from these data $m_{a}$ was obtained.

Now

$$
m_{a}=V_{a} d_{a}
$$

where $d_{a}$ is the density of dry air at the pressure and temperature of $V_{a}$, the volume of dry air. In this particular setup, $V_{a}$ was measured by a laboratory wet gas meter at a temperature $t_{g}$.

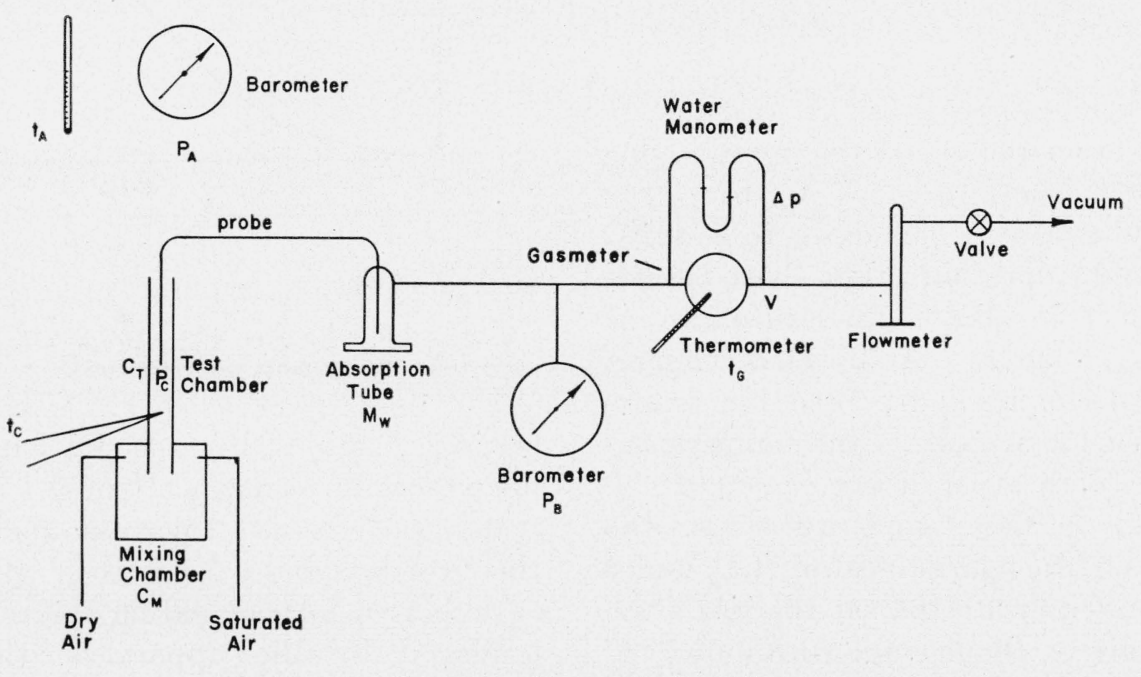

FiguRE 6. Diagram of gravimetric calibration setup. 
This gasmeter completely saturates the air passing through it so that the partial pressure of the dry air in the gasmeter is given by $P_{B}-p_{g}-1 / 2 \Delta p$, where $P_{B}$ is the pressure at the inlet to the gas meter, $p_{g}$ is the saturation pressure of water vapor at the temperature, $t_{g}$, of the air in the gas meter, and $\Delta p$ is the pressure drop across the gas meter. The weight of the dry air in the sample, in terms of observable data and the density of dry air under standard conditions, becomes

$$
m_{a}=\frac{V_{a}\left(P_{B}-p_{g}-1 / 2 \Delta p\right)(0.001293)(273.1)}{760\left(273.1+t_{g}\right)} .
$$

Substituting from eq 13 and 11 into eq 7 yields the desired expression for the relative humidity in the test chamber in terms of known and measurable quantities

$$
H=\frac{P_{A} / p_{s w}}{1+\frac{V_{a}\left(P_{B}-p_{g}-1 / 2 \Delta p\right)(0.00028898)}{m_{w}\left(273.1+t_{g}\right)} .}
$$

With the proportioning valve set to produce a relative humidity of 100 percent, and the pressure regulator adjusted to give an air velocity in the test chamber of $525 \mathrm{ft} / \mathrm{min}$, a number of gravimetric determinations was made in the temperature range of $-10^{\circ}$ to $-40^{\circ} \mathrm{C}$. Then with the air velocity maintained at $525 \mathrm{ft} / \mathrm{min}$, and at an ambient temperature of $-10^{\circ} \mathrm{C}$, a run was made at each setting of the proportioning valve. Finally, at an ambient temperature of $-10^{\circ} \mathrm{C}$ and with the proportioning valve set at 100 per. cent, two runs were made, one at an air velocity of $850 \mathrm{ft} / \mathrm{min}$ and the other at $1,140 \mathrm{ft} / \mathrm{min}$.

\section{Procedure and Results}

In making a gravimetric determination, the humidity apparatus was set into operation and brought to equilibrium conditions. The sample of air was withdrawn by the glass probe at the rate of 1 liter per minute. An attempt was made to collect $50 \mathrm{mg}$ of water vapor in the absorption tube. This required withdrawing air for periods varying from $1 / 2$ to $10 \mathrm{hr}$. The weight of the water was determined with an accuracy of $1 / 2$ to 1 percent.

For the duration of the run, frequent readings were made at equal time intervals of the temperatures and pressures. The pressure, $P_{B}$, at the inlet of the gas meter was determined with an accuracy of $\pm 0.2 \mathrm{~mm} \mathrm{Hg}$ and the atmospheric pres- sure, $P_{A}$, was determined with an accuracy of $\pm 0.1 \mathrm{~mm} \mathrm{Hg}$, both by means of precision aneroid barometers. A mercury-in-glass thermometer, accurate to $0.1 \mathrm{deg}$, gave the temperature, $t_{\mathrm{g}}$, of the air in the gas meter. A water manometer that could easily be read to $1 / 2 \mathrm{~mm}$ or better was used to obtain the pressure drop, $\Delta p$, across the gas meter.

The results of these determinations are given in table 1 , based upon the saturation pressures with respect to ice presented in the Smithsonian Tables, ${ }^{4}$ in Wärmetabellen, ${ }^{5}$ and in Goff's table. ${ }^{6}$ It is estimated that the vapor pressures have been gravimetrically determined with an accuracy of 1 to 2 percent. The difference, $D$, without regard to sign, between each test result and the setting of the proportioning valve is also given. The differences depend upon the vapor pressure tables used in the computation. The best agreement between the gravimetric determinations and the valve settings of the humidity apparatus is obtained by utilizing the Wärmetabellen values of vapor pres-

\begin{tabular}{|c|c|c|c|c|c|c|c|c|c|}
\hline \multirow{3}{*}{$\begin{array}{l}\text { Run } \\
\text { num- } \\
\text { ber }\end{array}$} & \multirow{3}{*}{$\begin{array}{c}\text { Satura- } \\
\text { tion } \\
\text { temper- } \\
\text { ature }\end{array}$} & \multirow{3}{*}{\begin{tabular}{|c|} 
Air \\
veloc- \\
ity
\end{tabular}} & \multirow{3}{*}{$\begin{array}{c}\text { Pro- } \\
\text { por- } \\
\text { tion- } \\
\text { ing } \\
\text { valve } \\
\text { set- } \\
\text { ting }\end{array}$} & \multicolumn{6}{|c|}{ Relative humidity } \\
\hline & & & & \multicolumn{2}{|c|}{$\begin{array}{l}\text { Smithso- } \\
\text { nian }\end{array}$} & \multicolumn{2}{|c|}{$\begin{array}{c}\text { Wärmeta- } \\
\text { bellen }\end{array}$} & \multicolumn{2}{|c|}{ Goff } \\
\hline & & & & Result & $D$ & Result & $D$ & Result & $D$ \\
\hline & ${ }^{\circ} \mathrm{C}$ & $\mathrm{ft} / \min$ & $\%$ & $\%$ & $\%$ & $\%$ & $\%$ & $\%$ & $\%$ \\
\hline 1 & -10.30 & 525 & 100 & 100.6 & 0.6 & 101.6 & 1. 6 & 101.5 & 1.5 \\
\hline 8 & -11.09 & 525 & 100 & 97. 3 & 2. 7 & 98.2 & 1.8 & 98.1 & 1. 9 \\
\hline 9 & -11.01 & 525 & 100 & 94.9 & 5.1 & 95.8 & 4. 2 & 95.7 & 4. 3 \\
\hline 10 & -11.30 & 525 & 100 & 94.1 & 5. 9 & 95.0 & 5.0 & 94.9 & 5. 1 \\
\hline 1a & -14.57 & 525 & 100 & 98.9 & 1.1 & 100.0 & 0.0 & 100.0 & 0.0 \\
\hline 5 & -28.65 & 525 & 100 & 96. 6 & 3.4 & 99.1 & .9 & 97.6 & 2.4 \\
\hline 6 & -28.61 & 525 & 100 & 98.0 & 2.0 & 100.3 & .3 & 99.1 & 0.9 \\
\hline 7 & -40.94 & 525 & 100 & 94.4 & 5. 6 & 99.6 & .4 & 94.4 & 5. 6 \\
\hline 11 & -39.77 & 525 & 100 & 96.0 & 4.0 & 99.1 & .9 & 96.3 & 3. 7 \\
\hline 2 & -10.30 & 525 & 83.3 & 81.3 & 2.0 & 82.2 & 1.1 & 82.0 & 1. 3 \\
\hline 3 & -10.10 & 525 & 66.7 & 633 & 3.4 & 63.9 & 2.8 & 63.8 & 2. 9 \\
\hline 4 & -10.02 & 525 & 50.0 & 49. 7 & 0.3 & 50.2 & 0.2 & 5). 2 & 0.2 \\
\hline 12 & -10.50 & 525 & 33.3 & 32.9 & .4 & 33.2 & .1 & 33.2 & .1 \\
\hline 13 & -10.48 & 525 & 16. 7 & 15.4 & 1.3 & 15.5 & 1. 2 & 15.5 & 1. 2 \\
\hline 14 & -10.01 & 525 & 0 & 0.4 & 0.4 & 0.4 & 0.4 & 0.4 & 0.4 \\
\hline 15 & -10.36 & 850 & 100 & 94.2 & 5. 8 & 95.6 & 4. 4 & 95.5 & 4.5 \\
\hline 16 & -10.75 & 1,140 & 100 & 102. 3 & 2. 3 & 103. 3 & 3. 3 & 104. 6 & 4. 6 \\
\hline $1 b$ & -14.42 & 525 & 66. 7 & 64.2 & 2. 5 & 64.9 & 1.8 & 64.9 & 1.8 \\
\hline Avg .. & - & .... & - & - & 2. 7 & - & 1. 7 & $\cdots$ & 2. 4 \\
\hline
\end{tabular}

TABLE 1. Gravimetric calibration

${ }^{4}$ Smithsonian Meteorological Tables, 5th ed. (1939).

${ }_{5}^{5}$ L. Holborn, K. Scheel, and F. Henning, Wärmetabellen der PhysikalischTechnischen Reichsanstalt (1919).

${ }^{6}$ John A. Goff, ASHVE Journal Section; Heating, piping, and air conditioning, 355 (June 1945). 
sure. The average difference between the valve settings and the test results for the temperature range of $-10^{\circ}$ to $-40^{\circ} \mathrm{C}$ and for air velocities up to $1,140 \mathrm{ft} / \mathrm{min}$, based on the Warmetabellen is 1.7 percent, on Goff's table is 2.4 percent, and on the Smithsonian tables is 2.6 percent. These results show that the humidity apparatus, over the temperature and velocity ranges tested, produced air having a relative humidity that averaged within 3 percent of the orifice ratio setting of the proportioning valve.

\section{Discussion}

This apparatus is particularly suited for the investigation and calibration of hygrometers, psychrometers, and dewpoint apparatus at temperatures below $0^{\circ} \mathrm{C}$. The rotation of the proportioning valve and the adjustment of the pressure equalization valves are the only operations necessary for changing the relative humidity. The time involved is usually a matter of 1 or 2 seconds. This readily permits any device under test to be subjected to a sudden discontinuous change in relative humidity, a desirable advantage in the study of lag characteristics. The air velocity in the test chamber can easily be adjusted to any value up to $1,500 \mathrm{ft} / \mathrm{min}$ within several seconds by adjusting the pressure regulator. The size of an object that can be tested is limited by the inside diameter of the test chamber, which is $1 \frac{1 / 8}{8}$ in. For applications where high air velocities are not necessary, the diameter of the test chamber may be increased to allow larger devices to be inserted.

There is no provision in the apparatus for introducing discrete and rapid changes in ambient temperature. To change the ambient temperature may require up to an hour to reach equilibrium conditions.

There are two ways in which this apparatus may be used to produce known dewpoints. If the proportioning valve is set to 100 , then the emerging air will have a dewpoint equal to the test chamber temperature, or, more closely, to the temperature of the air in the final saturator. A change in dewpoint is made by altering the bath temperature. On the other hand, if recourse to standard vaporpressure tables and eq 4 is made, then for any given bath temperature, several vapor pressures, equivalent to dewpoints at temperatures below that of the bath, are obtainable by rotation of the proportioning valve. The dewpoints thus obtained may have an average error of $0.3 \mathrm{deg} \mathrm{C}$ based on an average error in the humidity of 3 percent.

The author thanks R. B. Kennard, for designing the proportioning valve and preliminary models, and E. G. Clarke for constructing some of the units, especially the saturators.

Washington, March 3, 1948. 